\title{
Mining Engineers Training: Case Study Method
}

\author{
Svetlana Kolomiets ${ }^{1, *}$, Elena Medvedeva ${ }^{2}$, and Alena Perevalova $^{1}$ \\ ${ }^{1}$ Kemerovo State University, Institute of Philology, Foreign Languages and Media Communication, \\ Department of Foreign Languages, 650000, 6 Krasnaya st., Kemerovo, Russian Federation \\ ${ }^{2}$ Kemerovo State Medical University, Foreign Students Office, 650056, 22A Voroshilova st., \\ Kemerovo, Russian Federation
}

\begin{abstract}
Currently, the minerals' extractive industries are going through a deep technological modernization, with a characteristic expansion of international exchange of knowledge and know-how. The unification of the equipment used in open-pit and underground mining, the global spread of advanced mining technologies increases the importance of the linguistic competencies of mining engineers. At the same time, the specifics of training mining engineers is the uniqueness of situations in the extraction and processing of mineral resources, which actualizes the case study method in the training of mining engineers. The paper provides a description of the term "case study» and its basic characteristics and principles of application. The content is based on the authors' own experience of mining engineers in case studies while teaching English. Some examples of case studies for mining engineering students studying English are presented. The paper notes the effectiveness of implementing case study method and shows its benefits for introducing in the process of mining engineers training. In addition to listing positive effects of the method for developing skills necessary for competitive specialists such as critical thinking, problem solving, creativity, collaboration, etc., the authors mention possible problems that are likely to occur while using this method as well.
\end{abstract}

\section{Introduction}

The era of globalization and fast technological development sets new targets before the industrial enterprises of different sectors of economy. Coal mining industry which is the leading one in Kuzbass is currently undergoing the process of modernization. The changes taking place in the industrial enterprises are inseparably connected with the urge for the specialists of a modern type as one of the main resources of any successful business is its personnel. The chief managers of the coal industry companies stress the importance of increasing the level of professional skills, developing the ability to update and obtain modern knowledge and skills, learn best practices and methods of solving problems [1]. So, the task of training competitive specialists possessing the skills necessary in the $21^{\text {st }}$ century has become one of the most urgent. These can be grouped under the "7Cs" skills of the $21^{\text {st }}$ century learning which include:

\footnotetext{
* Corresponding author: kolomsvetlana@yandex.ru
} 
- Critical thinking and problem solving;

- Creativity and innovation;

- Collaboration, teamwork and leadership;

- Cross-cultural understanding;

- Communications, information and media literacy;

- Computing and ICT literacy;

- Career and learning self-reliance. [2]

While achieving the development of these skills, educators have to give priority to interdisciplinary relations. In this connection educational area of foreign language provides necessary opportunities for it, being one of the key subjects for any professional nowadays and presenting a platform for applying both modern information technologies and knowledge of other subject areas.

\section{Materials and Methods}

Giving the analysis of the existing approaches to the teaching a foreign language some researches note that andragogical learning model should be used to choose the most effective training methods. According to this model a teacher should follow the principles below:

- using personal and professional experience of the trainees;

- practicing individual approach and flexibility in the curriculum development;

- giving priority to self-learning;

- practically applying the knowledge and the skills developed [3].

Taking into consideration the principles of andragogical learning model and skills of the $21^{\text {st }}$ century learning we come to a limited set of interactive teaching methods enabling to meet our demands. One of them, using MOOCs in the process of study which proves to be very effective when properly organized and provides wide opportunities to the development of all the necessary skills [4]. The usage of IT (Web 2.0 technologies) while teaching English to the mining specialists has also proved its efficiency in the sphere of creativity, collaboration, cross-cultural understanding, communicating and information literacy, computing and ICT literacy [5]. The interactive teaching methods can also be successfully employed in various creative workshops for students to diversify a class activity and direct the students' interests to professional self-education [6].

Yet, in this paper we want to focus on one more teaching method - the method of case studies which can be an integral part of all mentioned above.

The case study teaching method has gained popularity in recent years as it meets the need of up-to-date higher education to boost students' participation in learning both in the classroom and outside. The emphasis on active learning in modern education is the main reason for incorporating case studies in the training of mining engineering students.

The case study teaching method is a highly adaptable style of teaching that involves problem-based learning and promotes the development of analytical skills. Case studies are used to conduct effective training and professional orientation of students. They help to intensify the learning process and to encourage students to participate creatively. Using case studies promotes critical thinking, learning and participation among students especially in terms of the ability to view an issue from multiple perspectives and to grasp the practical application of core course concepts [7,8].

Case studies were first used in the Harvard Law School in 1871 [9]. Since then, case study as a teaching methodology has been employed for many decades and has proven to be a useful pedagogical tool. Today, the case study is widely used as a teaching method in the scope of disciplines such as medicine, psychology, sociology, economics, management, foreign language and others where the presentation and analysis of real and realistic 
problems encourage students to apply the gained theoretical knowledge to solve some practical professional issues. In other words, case studies provoke the application of theoretical knowledge to real or realistic professional issues.

There are a number of definitions for the term case study. In its most naive form, it simply refers to a realistic example used to illustrate a concept or technique [10]. Case studies are complex examples which give an insight into the context of a problem as well as illustrating the main point. Case studies are student centered activities based on topics that demonstrate theoretical concepts in an applied setting.

We view case studies as real world issues closely connected with students' future professional sphere that stimulate students' critical thinking and put them in the position of a decision-maker.

Case studies can be used to:

- allow the application of theoretical concepts to be demonstrated, thus bridging the gap between theory and practice;

- encourage active learning;

- provide an opportunity for the development of key skills such as communication, group working and problem solving;

- increase the students' enjoyment of the topic and hence their desire to learn [11].

A case is basically a story that illustrates a general problem or particular principle. A case recounts events or problems in a way that students can learn from their complexities. Case study teaching involves the use of real situations or they can be constructed by a teacher from newspaper articles, TV shows, book stories and even advertisements. A good case study, according to Professor Paul Lawrence is: "the vehicle by which a chunk of reality is brought into the classroom to be worked over by the class and the instructor. A good case keeps the class discussion grounded upon some of the stubborn facts that must be faced in real life situations." [13].

A case study must contain an account (often in a scenario format - a story) of a realworld activity, event, or situation. It might be supported with background material (setting, personalities, sequence of events, and problems and conflicts), artifacts, and data, which is relevant to the situation depicted [10]. David B. G in her works emphasizes the necessity for a case to require emotional as well as intellectual engagement [12].

By presenting content in the format of a narrative accompanied by questions and activities that promote group discussion and solving of complex problems, case studies encourage students to make choices about what theories or concepts they read in textbooks or heard at lectures apply to the solution of the problem.

In classroom discussion, students analyze the information in the case and use it to solve the problem set up by the case. The discussion can take many forms, including closely directed questioning by faculty to help students draw out the information from the case and identify the central decisions or evaluations that need to be made, more open-ended questions and discussions as students evaluate options and weigh the evidence, and small group work by students focused on specific analytical tasks [14].

Davis B. G. suggests the following steps in working with cases at lessons:

Begin by situating the case in the context of the course.

Introduce the case, or have a student introduce it.

Start the discussion by asking a general question.

Adopt a nondirective, facilitative role.

Have a team of students lead the discussion.

Summarize key points and help students understand what they have learned.

For a real - life case, reveal the real - life conclusion.

Have students write about the case.

Ask students to evaluate the discussion [12]. 
Due to the creative nature of a case study, it is often difficult to see the success or failures of a case method right away. Nevertheless, each time a teacher includes a case study in a course, it is important to assess what the students have learned. A teacher can choose one from the two main modes of assessment that are formative or summative. Formative assessment implies the assessment for the purpose of improving learning and student performance while the summative one means the evaluation of student performance against a set of predetermined standards. Summative assessment is used to assess the students' understanding of course content, while a formative approach is employed for evaluating key skills development and giving feedback to encourage students to reflect upon their learning experience [11].

As it was mentioned above the case teaching method has been used effectively in many courses (law, medicine, and business) to teach how to solve problems and make decisions, while dealing with realistic situations. Using case study teaching perfectly meets the needs of professional training in English as case studies at English classes facilitate interdisciplinary learning and promote the practice of language skills in professional sphere.

Teaching professionally oriented communication using a case study teaching method requires that both the teacher and students possess a number of developed professional communicative abilities. They are:

- ability to perceive and evaluate the information coming in both verbal and non-verbal form;

- ability to carry out diagnostics and analysis of the problem;

- ability to formulate and logically construct a statement in compliance with the rules of language;

- ability to take part in a discussion;

- ability to participate in collective decision-making [15].

At English classes students are exposed to solving case studies in the sphere of business and engineering. The examples of cases for mining students described below illustrate typical cases that can be employed during the course of Business English.

The first case refers to the topic «Business meeting».

The title of the case is «Visitors from China».

\section{Results and Discussion}

Implementing a case study in the educational process promotes high-quality training of specialists in the field of mining as it has proven to develop their ability to analyze the situation, plan strategy and make decisions. Additionally, it encourages improving professional skills, such as analytical (classify, highlight, analyze), creative, communicative, social (listen to and hear, interact and communicate, persuade), and practical ones (use academic theories, methods and principles in practice). Moreover, employing a case study promotes the development of students' value system, professional and life attitudes.

When using the case study method for teaching a foreign language, students deal with the problem-based situations they have to analyze and find out ways to solve them. Such situations are much closer to real life than using traditional methods of teaching foreign languages for a future profession. They encourage the development of students' selfreflective thinking, ability to hear and take into account an alternative point of view, express their own position in a well-argued manner that is highly required in their future professional activity. Owing to this method, students have had an opportunity to exercise and improve analytical and evaluation skills, learn to work in a team, find the most effective way to sort out a problem, master the ability to use obtained knowledge in practice. 
Using the case study method for teaching a foreign language to mining engineers allows students to understand real situations of professional activity and to update a certain set of knowledge that needs to be learned when solving the problem. Implementing such cases as 'Designing equipment for search, extraction and transportation of natural minerals', 'Technological hazards: industrial accidents', 'Geological survey expedition' in the English lesson classroom motivates, stimulates and contributes to obtaining information processing skills, solving practical problems that students could come across in the future professional work environment. Such experiential learning strengthens students' confidence, self-esteem, responsibility and the ability to work in a team, as well as contributes to the improvement of their communication skills, knowledge of the academic discipline and the development of cognitive abilities.

Furthermore, the use of this method gives students the opportunity to get acquainted with the experience of mining companies, take a positive attitude towards future professional activity, increase their level of professional competence, as well as acquire the skills in analyzing taken decisions, skills in strategy and tactics development. Simulating a problem situation at work, anticipating its consequences and ways out make students think, discuss and draw conclusions. All this generates an internal impulse and also contributes to the strengthening cognitive interests.

The authors' practical experience in developing and integrating case studies into the educational process allows us to draw some conclusions and state some difficulties.

Despite its effectiveness, the case study method should not completely replace other traditional forms and methods of teaching (lectures, seminars and practical classes), but diversify them. The ratio between cases and other teaching methods used in the classroom should be chosen by the teacher, as it depends on different factors including the availability of appropriate and engaging cases on the course topics. The teacher decides which case suits each topic the best. It depends on the purpose of the lesson as well as the skills to be developed in the learning process.

In order to achieve a significant effect of using the case study method it is necessary for students to (individually or in small groups) get ready for the case discussion before the lesson. It helps them carefully think over all the arguments before bringing them up in the classroom.

The teacher is required to set achievable goals, tasks and a detailed plan of each lesson, carry out careful scheduling and tracking time during the learning process. Insufficient control over the time spent on the case can result in prolongation of the discussion and, as a consequence, failure to reach the objectives.

It is essential to choose or create cases taking into account different levels of students' language proficiency and their experience in sorting out such tasks. The process of implementing the case study method should start with easier tasks to more complicated specific ones.

It should be also mentioned that classrooms equipped with modern technical training tools, multimedia learning aids and availability of the Internet can facilitate access to data necessary for solving case studies.

We are convinced that involving specialists working in the mining industry in creating a bank of cases will provide benefits and be considerably helpful in students' future professional activity.

To sum up, using the case study method in the learning process encourages developing communicative skills as well as prepares students for future professional activity. The survey of students of mining engineering specialties has allowed to get feedback on the effectiveness of implementing cases in the process of learning a foreign language. The results of the survey let us conclude that their use has contributed to: 
- an increase in motivation and an interest in future profession as well as in studying a foreign language ( $92 \%$ of the total number of respondents);

- overcoming the psychological barrier of insecurity and fear $(85 \%$ of the students surveyed);

- easier acquisition of professional vocabulary, rather than memorizing terms $(79 \%$ of the students);

- mastering the skills of public speaking ( $71 \%$ of the students);

- developing the skills to hold a discussion, give reasons for their opinions, provide alternative solutions to a problem ( $68 \%$ of the total number of respondents);

- ability to work in a team and develop a collective solution ( $62 \%$ of the students surveyed);

- ability to work independently with a large amount of information, process, generalize and systematize the facts ( $59 \%$ of the students).

\section{Conclusion}

Case studies are aimed to encourage students' and limit teacher's participation in a class. Cases are actively employed in an active learning and student-centered approach where the teacher acts as a facilitator or a coach. In comparison with classical teaching methods, casestudy approach more successfully develops students' reasoning and problem-solving skills, the ability to make objective judgements, the ability to identify the relevant issues and recognize multiple perspectives. They are most often used to enhance students' awareness of their future profession field and experience professional practice. Thus the main idea of the case study teaching method is to encourage improving professional skills (analytical, creative, practical) along with communicative and social ones. As for English classes is concerned case studies facilitate interdisciplinary learning and promote the practice of language skills in professional sphere as well.

It's notable that to succeed in using this method both the teacher and the students should possess a number of developed professional communicative abilities, otherwise it's necessary to start with small case-like tasks to ensure their development. Besides, each case needs to be carefully planned taking into account the target audience and training needs. In this case it allows to strengthen students' confidence, self-esteem, responsibility and the ability to work in a team, as well as improves their communication skills, knowledge of the academic discipline and develops cognitive abilities

Being one of the most promising interactive methods of teaching, case study still have some drawbacks. The main problem is choosing the right case for teaching needs as the number of cases designed for using in the classroom of English and covering the particular professional area is limited. So, it's necessary to create the bank of cases to use and involve specialists working in the industry both to creating tasks and to evaluating the solutions proposed.

To sum it all up, despite the necessity of thorough planning, proper assessing of the target audience level and demands, case study method act as a great stimulus for intellectual activity of future mining engineers and encourage their desire for further self-education and implementation of obtained skills both at the working place and in the process of study.

\section{References}

1. V. Bobrikov, N. Ravochkin, V. Shchennikov, E3S Web of Conf., 41, 04014 (2018)

2. B. Trilling, Ch. Fadel, 21st Century Skills. Learning for life in our times (Jossey-Bass, New York, 2009) 
3. E. Bondareva, G. Chistyakova, Yu. Kleshevskyi, S. Sergeev, A. Stepanov, E3S Web Conf., 21, 04019 (2017)

4. I. Saveleva, O. Greenwald, S. Kolomiets, E. Medvedeva, E3S Web Conf., 21, 04024 (2017)

5. A. Perevalova, E3S Web Conf., 41, 04030 (2018)

6. O. Solnyshkova, E. Boiko, MATEC Web Conf., 170, 01055 (2018)

7. C. F. Herreid, N. A. Schiller, K. F. Herreid, C. Wright, J. Col. Sci. Teach., 40:4 (2011)

8. A. Yadav, M. Lundeberg, M. DeShryver, K. Dirkin, N. A. Schiller, K. Maier, C. F. Herreid, J. Col. Sci. Teach., 37:1 (2007)

9. A. M. Tomey, Journal of Continuing Education In Nursing, 34:1 (2003)

10. T. B. Hilburn, M. Towhidnejad , S. Nangia, L. Shen Frontiers in Education, 1, 1-5 (2006)

11. C. Davis, E. Wilcock, Teaching Materials Using Case Studies, (Ashley Printer: London, 2003)

12. B. G. Davis, Case Studies. Tools for Teaching, (Jossey-Bass, San Francisco, 2009)

13. E. F. Barkley, K. P. Cross, C. H. Major, Collaborative Learning Techniques: A Handbook for College Faculty, (Jossey-Bass, San-Francisco, 2005)

14. What is Teaching with the Case Method? URL: https://serc.carleton.edu/sp/library/cases/what.html

15. T. G. Beckisheva, G. A. Gasparyan, N. Kovalenko, Procedia: Social and Behavioral Sciences, 166, 00127 (2015) 